\title{
Purinergic P2 Receptors Modulate Excitability But Do Not Mediate pH Sensitivity of RTN Respiratory Chemoreceptors
}

\author{
Daniel K. Mulkey, Akshitkumar M. Mistry, Patrice G. Guyenet, and Douglas A. Bayliss \\ Department of Pharmacology, University of Virginia, Charlottesville, Virginia 22908
}

\begin{abstract}
The cellular mechanism(s) by which the brain senses changes in $\mathrm{pH}$ to regulate breathing (i.e., central chemoreception) have remained incompletely understood, in large part because the central respiratory chemoreceptors have themselves eluded detection. Here, we recorded from a newly identified population of central chemoreceptors located in the retrotrapezoid nucleus (RTN) on the ventral surface of the brainstem to test a recently proposed role for purinergic P2 receptor signaling in central respiratory chemoreception (Gourine et al., 2005). Using loose-patch current-clamp recordings in brainstem slices from rat pups (postnatal day 7-12), we indeed show purinergic modulation of pH-sensitive RTN neurons: activation of P2X receptors indirectly inhibited RTN firing by increasing inhibitory input, whereas P2Y receptor stimulation caused direct excitation of RTN chemoreceptors. However, after blocking P2 receptors with the broad-spectrum antagonists PPADS (pyridoxal-phosphate-6-azophenyl-2',4'-disulfonate) or RB2 (reactive blue 2), the pH sensitivity of RTN neurons remained intact. Therefore, we conclude that purinergic signaling can modulate RTN neuron activity but does not mediate the $\mathrm{pH}$ sensing intrinsic to these central respiratory chemoreceptors.
\end{abstract}

Key words: chemosensitivity; purinergic signaling; central respiratory control; ventral medullary surface; $\mathrm{pH}$ signaling; brain slice

\section{Introduction}

Central respiratory chemoreception is the mechanism by which the brain senses changes in $\mathrm{CO}_{2}$ and/or $\mathrm{pH}$ to regulate the rate and depth of breathing (Feldman et al., 2003). Despite intensive effort, the cellular mechanisms responsible for sensing $\mathrm{pH}$ in the context of respiratory control remain unknown, in part because of difficulties in identifying neurons that function as chemoreceptors. We recently identified a group of highly $\mathrm{pH}$-sensitive neurons located near the ventral surface of the medulla oblongata, within the retrotrapezoid nucleus (RTN), that have characteristics expected of central respiratory chemoreceptors [i.e., these cells display an intrinsic and robust sensitivity to changes in $\mathrm{CO}_{2} / \mathrm{H}^{+}$in vivo and in vitro, and they send excitatory projections directly to the respiratory central pattern generator (Mulkey et al., 2004)]. We found that RTN chemoreceptor neurons express a $\mathrm{pH}$-sensitive and relatively voltage-independent $\mathrm{K}^{+}$current (Mulkey et al., 2004), suggesting a role for background $\mathrm{K}^{+}$channels in the mechanism by which respiratory chemoreceptors sense changes in $\mathrm{pH}$. However, this observation does not exclude the possibility that the $\mathrm{pH}$ sensitivity of the background $\mathrm{K}^{+}$channel is secondary to actions of another signaling element (e.g., a factor released locally during acidification that inhibits the $\mathrm{K}^{+}$ channel) or that alternative $\mathrm{pH}$-sensitive mechanisms contribute to the integrated output of RTN chemoreceptors.

Activation of purinergic signaling represents one such alter-

Received April 20, 2006; revised May 22, 2006; accepted May 23, 2006.

This work was supported by National Institutes of Health Grants F32 HL80890 (D.K.M.), HL74011 (P.G.G.), and NS33583 (D.A.B.)

Correspondence should be addressed to Daniel K. Mulkey, University of Virginia Health System, P.0. Box 800735, 1300 Jefferson Park Avenue, Charlottesville, VA 22908. E-mail: dm5up@virginia.edu. DOI:10.1523/JNEUROSCI.1696-06.2006

Copyright $\odot 2006$ Society for Neuroscience $\quad$ 0270-6474/06/267230-04\$15.00/0 native mechanism for $\mathrm{CO}_{2} / \mathrm{H}^{+}$sensing in neuronal systems. For example, extracellular levels of adenosine and ATP are influenced by the prevailing interstitial $\mathrm{pH}$ in hippocampal slices and, via $\mathrm{P} 1$ (adenosine) and/or P2 (ATP) purinergic receptors, these endogenous purines can alter hippocampal neuron excitability (Dulla et al., 2005). Of particular relevance, it was recently proposed that ATP release and P2 receptor signaling contribute to central respiratory chemoreception (Gourine et al., 2005). Specifically, it was demonstrated that hypercapnia evoked release of ATP at various sites on the ventral medullary surface, including within regions that overlap with the RTN. Moreover, application of ATP to the ventral surface of the brainstem stimulated respiratory output, whereas the P2 receptor antagonist pyridoxal-phosphate-6azophenyl-2', $4^{\prime}$-disulfonate (PPADS) decreased the respiratory responses to changes in $\mathrm{CO}_{2}$ (Gourine et al., 2005). These results suggest that ATP release and $\mathrm{P} 2$ receptor stimulation contribute to the integrated respiratory response to hypercapnia in vivo. However, the data do not address whether ATP actions reflect an interaction with the $\mathrm{pH}$ sensing mechanism per se or a more general modulatory action on the chemoreceptor cells (or other neurons within the respiratory network).

In this work, we used a brain slice preparation to determine directly the effects of $\mathrm{P} 2$ receptor signaling on functionally identified RTN chemoreceptors and on their sensitivity to changes in $\mathrm{pH}$. We find that $\mathrm{P} 2 \mathrm{X}$ and $\mathrm{P} 2 \mathrm{Y}$ receptors have opposing effects on RTN cell excitability (indirect inhibition and direct excitation, respectively) but that $\mathrm{pH}$ sensitivity is wholly retained during $\mathrm{P} 2$ receptor blockade. Thus, we conclude that purinergic signaling can modulate chemoreceptor output, but it does not mediate the $\mathrm{pH}$ sensing mechanism intrinsic to RTN central respiratory chemoreceptors. 


\section{Materials and Methods}

Brainstem slices. Neonatal rats (7-12 d postnatal) were decapitated under ketamine/xylazine anesthesia, and transverse slices $(300 \mu \mathrm{m})$ were prepared from brainstem using a microslicer (DSK 1500E; Dosaka, Kyoto, Japan) in ice-cold substituted Ringer's solution containing the following (in mM): 260 sucrose, $3 \mathrm{KCl}, 5 \mathrm{MgCl}_{2}, 1 \mathrm{CaCl}_{2}, 1.25 \mathrm{NaH}_{2} \mathrm{PO}_{4}, 26$ $\mathrm{NaHCO}_{3}, 10$ glucose, and 1 kynurenic acid. Slices were incubated for $\sim 30 \mathrm{~min}$ at $37^{\circ} \mathrm{C}$ and subsequently at room temperature in normal Ringer's solution (in mM): $130 \mathrm{NaCl}, 3 \mathrm{KCl}, 2 \mathrm{MgCl}_{2}, 2 \mathrm{CaCl}_{2}, 1.25 \mathrm{NaH}_{2} \mathrm{PO}_{4}$, $26 \mathrm{NaHCO}_{3}$, and 10 glucose. Both substituted and normal Ringer's solutions were bubbled with $95 \% \mathrm{O}_{2} / 5 \% \mathrm{CO}_{2}$.

Electrophysiology. Slices were transferred individually to a recording chamber mounted on a fixed-stage microscope (Axioskop FS; Zeiss, Oberkochen, Germany) and perfused continuously $(\sim 2 \mathrm{ml} / \mathrm{min})$ with a bath solution composed of the following (mM): $140 \mathrm{NaCl}, 3 \mathrm{KCl}, 2$ $\mathrm{MgCl}_{2}, 2 \mathrm{CaCl}_{2}, 10$ HEPES, and 10 glucose; the $\mathrm{pH}$ of the bath solution was adjusted between 6.9 and 7.5 by addition of $\mathrm{HCl}$ or $\mathrm{NaOH}$.

The RTN was identified by its location below the caudal end of the facial motor nucleus, and individual neurons were visualized using Nomarski optics. Neurons of interest had elongated somas with their long axis parallel to the ventral medulla surface and were typically located within $100 \mu \mathrm{m}$ of the ventral surface. Loose-patch recordings of membrane potential were made by using an Axopatch 200B patch-clamp amplifier, digitized with a Digidata 1322A analog-to-digital converter and recorded using pCLAMP 9.0 software (all from Molecular Devices, Union City, CA). Recordings were obtained at room temperature with patch electrodes pulled from borosilicate glass capillaries (Warner Instruments, Hamden, CT) on a two-stage puller (P89; Sutter Instrument, Novato, CA) to a DC resistance of 3-6 M $\Omega$ when filled with internal solution containing the following (mM): $120 \mathrm{KCH}_{3} \mathrm{SO}_{3}, 4 \mathrm{NaCl}, 1 \mathrm{MgCl}_{2}$, $0.5 \mathrm{CaCl}_{2}, 10$ HEPES, 10 EGTA, $3 \mathrm{Mg}$-ATP, 0.3 GTP-Tris, and $0.2 \%$ biocytin, pH 7.2; electrode tips were coated with Sylgard 184 (Dow Corning, Midland, MI). Firing rate histograms were generated by integrating action potential discharge in $10 \mathrm{~s}$ bins and plotted using Spike $5.0 \mathrm{soft}-$ ware (Cambridge Electronic Design, Cambridge, UK). Data were analyzed by paired $t$ test or by repeated-measures ANOVA.

Drug application. Low-resistance pipettes containing nonselective P2 receptor agonists (ATP or ATP $\gamma$ S), a P2X agonist $(\alpha, \beta$-methylene ATP, $\alpha, \beta$-MeATP), or a P2Y agonist, UTP (all at $1 \mathrm{~mm}$ in extracellular solution, $\mathrm{pH}$ 7.3) were connected to a picospritzer (Parker Instrumentation, Cleveland, $\mathrm{OH}$ ) and lowered into the vicinity of the recorded neurons for local pressure application. Application times were between 10 and $20 \mathrm{~s}$, and control experiments ensured that changes in firing were not attributable to pressure artifacts (i.e., pressure application of vehicle alone caused no change in firing rate, and measured effects on action potential discharge were blocked by $\mathrm{P} 2$ receptor antagonists). To block effects of $\mathrm{P} 2$ agonists and determine $\mathrm{P} 2$ receptor contributions to $\mathrm{pH}$ sensitivity in RTN neurons, we bath applied P2 receptor antagonists PPADS $(100 \mu \mathrm{M})$ or reactive blue 2 (RB2) $(20-50 \mu \mathrm{M})$. To determine whether effects of P2 receptor agonists on RTN neurons were mediated indirectly, via altered synaptic input, we bath-applied glutamate receptor antagonists 6-cyano7-nitroquinoxaline-2,3-dione (CNQX) $\left(\begin{array}{ll}10 & \mu \mathrm{M}\end{array}\right)$ and 2-amino-5phosphopentanoic acid $(\mathrm{APV})(50 \mu \mathrm{M})$ or glycine and $\mathrm{GABA}_{\mathrm{A}}$ receptor antagonists (strychnine, $20 \mu \mathrm{M}$; bicuculline, $10 \mu \mathrm{M}$ ).

\section{Results}

To examine contributions of purinergic signaling to central chemoreceptor function, it was first necessary to identify RTN neurons as chemosensitive by using their characteristic response to changes in bath $\mathrm{pH}$. This is illustrated in Figure $1 A$, in which an RTN neuron that was firing at $\sim 1 \mathrm{~Hz}$ under control conditions ( $\mathrm{pH} 7.30$ ) became silent when the bath was alkalized to $\mathrm{pH} 7.55$ and increased its firing to $>2 \mathrm{~Hz}$ during bath acidification ( $\mathrm{pH}$ 6.90). All neurons included in these studies showed similar responses to changes in extracellular $\mathrm{pH}(\mathrm{pH} 7.3,1.3 \pm 0.1 \mathrm{~Hz} ; \mathrm{pH}$ 7.5, $0.08 \pm 0.04 \mathrm{~Hz} ; \mathrm{pH} 6.9,3.0 \pm 0.3 \mathrm{~Hz} ; n=24)$. Acidification increased firing rate of these neurons by $164 \pm 20 \%$ from baseline
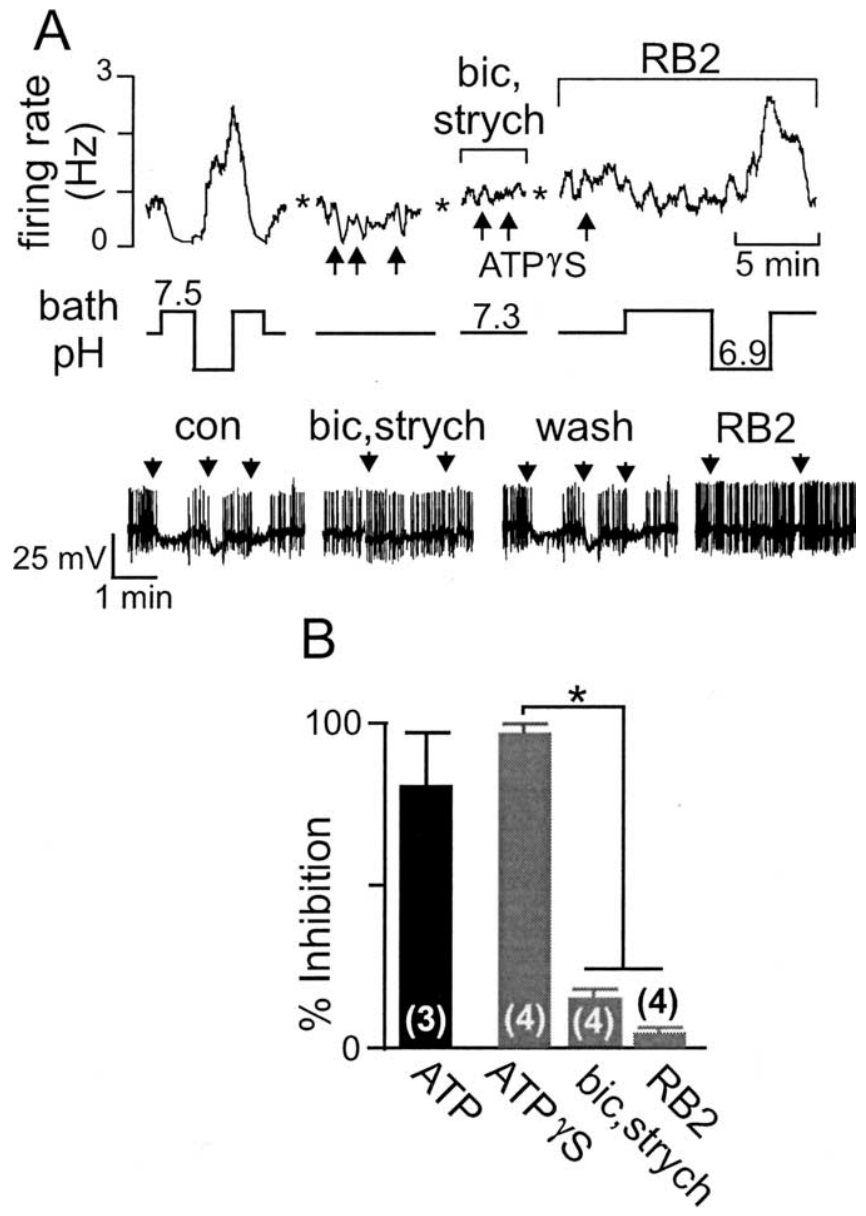

Figure 1. P2X-mediated inhibition of RTN chemoreceptors. $\boldsymbol{A}$, Firing rate plot obtained by loose-patch recording from a representative RTN neuron (top panel). The cell was identified as a chemosensitive neuron by a characteristic decrease in firing during bath alkalization (from $\mathrm{pH}$ 7.3 to 7.5 ) and increase in discharge during bath acidification (to $\mathrm{pH}$ 6.9). The firing rate was inhibited after local pressure application of ATP $\gamma S$, which can be more easily discerned in the membrane potential excerpts (bottom panel). The inhibition of cell firing induced by ATP $\gamma S$ was blocked by $\mathrm{GABA}_{\mathrm{A}}$ /glycine receptor antagonists [bicuculline (bic), $10 \mu \mathrm{m}$; strychnine (strych), $20 \mu \mathrm{m}$ ] and by the broad spectrum P2 receptor antagonist RB2 $(20 \mu \mathrm{m})$. Note, however, that pH sensitivity was retained in the presence of RB2 (asterisk indicates time breaks in firing rate plot; wash period depicted in excerpts was omitted from the firing rate plot). $\boldsymbol{B}$, Summary data illustrate the averaged percentage inhibition ( \pm SEM) of firing caused by ATP and ATP $\gamma S$; inhibition by ATP $\gamma \varsigma$ was absent during bath application of bicuculline/strychnine or RB2 ( ${ }^{*} p<0.001$, by ANOVA).

( $\mathrm{pH}$ 7.3), a pH sensitivity similar to that which we and others have reported previously for RTN chemosensitive neurons [e.g., $150 \pm 22 \%$ (Mulkey et al., 2004); $167 \pm 75 \%$ (Ritucci et al., 2005)].

\section{P2X-mediated inhibition of RTN chemoreceptors}

We tested effects on RTN firing rate evoked after local picospritzer application of ATP and ATP $\gamma \mathrm{S}$, two nonselective P2 receptor agonists. Invariably, ATP or its nonhydrolysable derivative ATP $\gamma \mathrm{S}$ inhibited activity of $\mathrm{pH}$-sensitive RTN neurons (Fig. $1 A, B)$. Because ATP $\gamma \mathrm{S}$ was as effective as ATP (Fig. $1 B$ ), the decrease in firing could not be explained by conversion of ATP to adenosine. We considered the possibility that the ATP-induced decrease in discharge might be caused by enhanced local release of inhibitory neurotransmitters. Indeed, as shown in Figure 1, $A$ and $B$, the inhibition of RTN neuron firing by $\mathrm{ATP} \gamma \mathrm{S}$ was apparently indirect because it was reversibly blocked by a $\mathrm{GABA}_{\mathrm{A}} /$ 


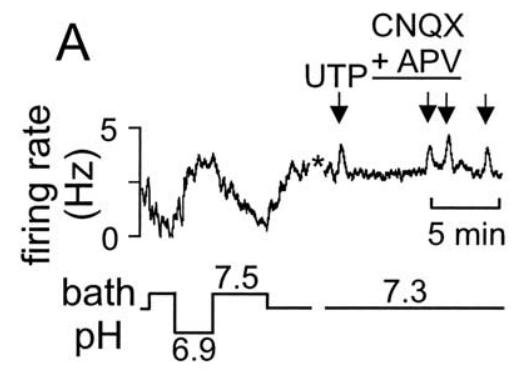

B

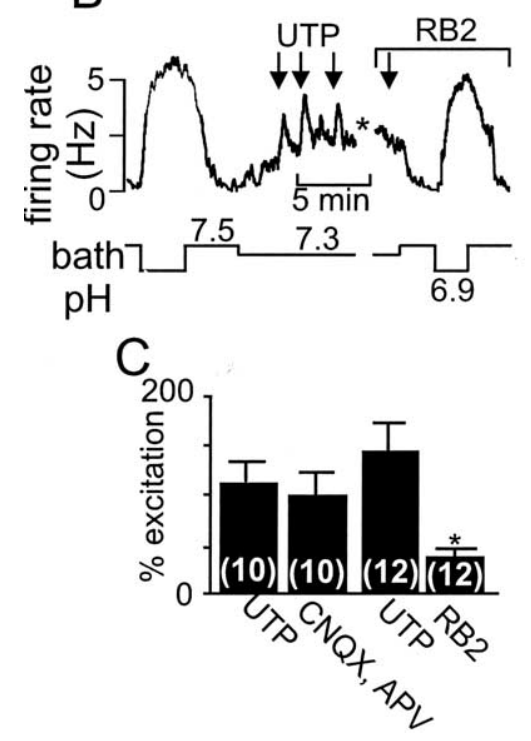

Figure 2. P2Y-mediated excitation of RTN chemoreceptors. $A$, Firing rate plot illustrates the excitatory effect of local pressure application of UTP $(1 \mathrm{~mm})$ in a representative $\mathrm{pH}$-sensitive RTN neuron; the UTP-evoked increase in firing was unaffected by block of ionotropic glutamate receptors with CNQX and APV (10 and $50 \mu \mathrm{M})$. $\boldsymbol{B}$, In a different pH-sensitive RTN neuron, the UTP-stimulated firing was blocked in the presence of RB2 $(50 \mu \mathrm{m})$, but pH sensitivity was retained. C, Summary data illustrating averaged ( \pm SEM) excitatory effects of UTP on RTN chemoreceptor neurons, under control conditions and during block of either glutamate receptors or $\mathrm{P} 2$ receptors $\left({ }^{*} p<0.05\right.$ by paired $t$ test).

glycine receptor antagonist cocktail (containing bicuculline and strychnine). The nonselective $\mathrm{P} 2$ receptor antagonist $\mathrm{RB} 2$ also abrogated ATP-induced inhibition of cell firing. Two observations suggest that suppression of firing by ATP was mediated by $\mathrm{P} 2 \mathrm{X}$ receptors. First, we found that inhibition was also mimicked by a $\mathrm{P} 2 \mathrm{X}$ receptor agonist, $\alpha, \beta$-MeATP $(58 \%, n=2)$. Second, we find that UTP, a P2Y-specific agonist (Ralevic and Burnstock, 1998), has the opposite effect on firing activity in these cells (see below). Note also that the RTN neuron continued to respond to changes in bath $\mathrm{pH}$ after blocking $\mathrm{P} 2$ receptors with $\mathrm{RB} 2$ (Fig. $1 A)$.

\section{P2Y-mediated excitation of RTN chemoreceptors}

To reveal additional effects of P2Y receptors on RTN chemoreceptor neurons, we applied UTP locally to $\mathrm{pH}$-sensitive neurons. As shown in Figure 2, $A$ and $B$, brief picospritzer application of UTP always increased firing rate in these cells. The excitatory effects of UTP were fully retained when excitatory synaptic transmission was blocked with glutamate receptor antagonists CNQX and APV (Fig. $2 A, C$ ), suggesting that effects on firing were not secondary to glutamate release. These actions of UTP could be attributed to P2Y receptors because effects of the P2Y agonist were virtually eliminated in the presence of RB2 (Fig. $2 B, C$ ).

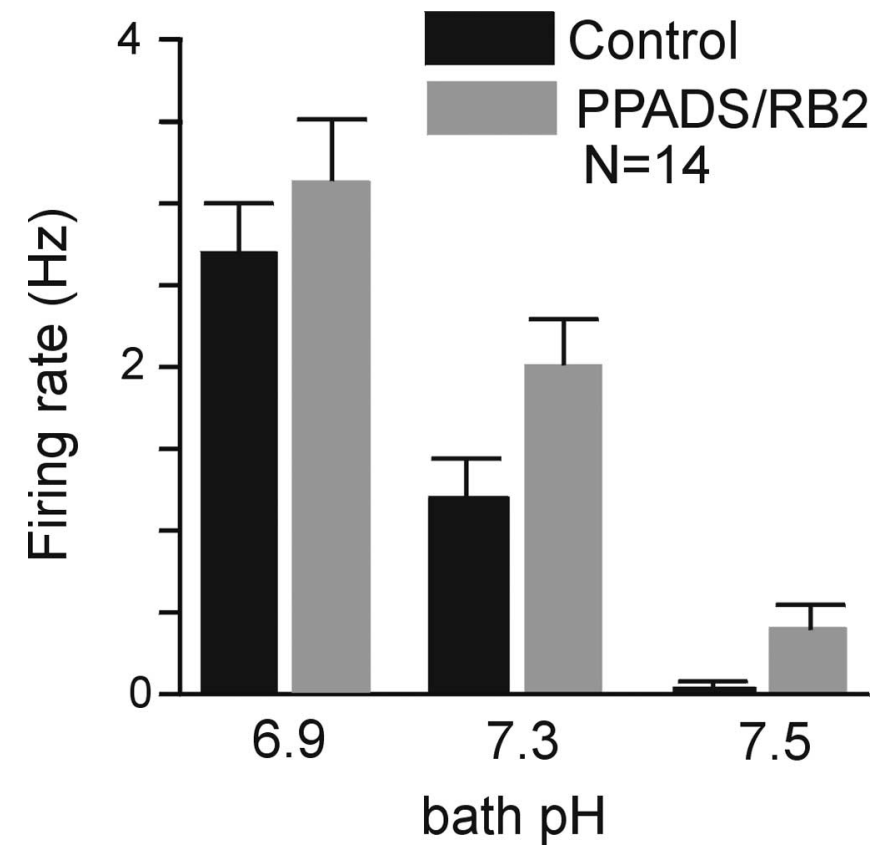

Figure 3. $\mathrm{P} 2$ receptors do not mediate $\mathrm{pH}$ sensitivity in RTN chemoreceptors. Summary data illustrating averaged ( \pm SEM) firing rate at normal pH (7.3) and during bath acidification ( $\mathrm{pH}$ 6.9) and alkalization ( $\mathrm{pH} 7.5)$, under control conditions and in the presence of the $\mathrm{P} 2$ receptor antagonists PPADS $(100 \mu \mathrm{m}, n=4)$ or RB2 $(20-50 \mu \mathrm{m}, n=10)$. There was no difference in $\mathrm{pH}$ sensitivity before or during $\mathrm{P} 2$ receptor blockade ( $p>0.25$ by two-way repeated-measures ANOVA); although firing rate was significantly higher in the presence of PPADS/RB2 ( $p<0.05$ by ANOVA), this difference was independent of prevailing $\mathrm{pH}$.

Note again that firing rate responses accompanying bath alkalization and acidification were preserved after $\mathrm{P} 2$ receptor blockade by $\mathrm{RB} 2$ in this representative RTN neuron (Fig. $2 B$ ).

\section{Chemosensitivity of RTN neurons does not require P2 receptors}

As depicted for the exemplar cells of Figures 1 and $2 B$, we examined the effects of bath acidification and alkalization on RTN firing activity before and after establishing P2 receptor blockade. We used either RB2 or PPADS as P2 receptor antagonists; although both were effective, we used RB2 for the majority of experiments because it seemed to provide a better block of UTPevoked firing responses (data not shown). In the population of RTN neurons tested under control conditions and in the presence of RB2/PPADS $(n=14)$, we found no difference in the $\mathrm{pH}$ sensitivity of RTN neurons (Fig. 3). Likewise, we observed no obvious differences in the kinetics of firing rate responses to changes in $\mathrm{pH}$. As is evident from the plot, absolute firing rate was slightly higher under all $\mathrm{pH}$ conditions in the presence of RB2 or PPADS. This could be attributable to abrogation of inhibitory effects of endogenously released ATP by the P2 receptor antagonists; alternatively, it might simply reflect a slight timedependent increase in firing over the course of the recording. In any case, these data indicate that purinergic signaling is not a critical component of the $\mathrm{pH}$ sensing mechanism in these RTN chemosensitive neurons.

\section{Discussion}

In this study, we tested the hypothesis that purinergic signaling contributes to the mechanism by which RTN chemoreceptors sense and respond to changes in $\mathrm{pH}$. Our data indicate that RTN chemoreceptor excitability is influenced by local activation of 
either P2X or P2Y receptors, but that RTN neuronal chemosensitivity itself is independent of $\mathrm{P} 2$ receptor signaling, i.e., firing rate responses to changes in extracellular $\mathrm{pH}$ were unaffected by $\mathrm{P} 2$ receptor blockade. Because RTN neurons are the most proximate candidate respiratory chemoreceptors, we conclude that P2 receptor-mediated enhanced respiratory output that accompanies local $\mathrm{CO}_{2}$-induced ATP release (Gourine et al., 2005) is not attributable to an effect on RTN chemoreception, per se. Rather, it appears that P2 receptor activation modulates RTN neuronal activity via at least two distinct mechanisms: presynaptic P2X receptors enhance release of GABA/glycine to inhibit RTN neurons, whereas activation of postsynaptic P2Y receptors causes direct excitation of those cells. In light of these results, we propose that a balance between ATP-evoked excitation and inhibition of central respiratory chemoreceptors, along with effects on other respiratory-related neurons within the region, will determine overall effects of hypercapnia-induced ATP release on whole animal respiratory responses to $\mathrm{CO}_{2}$ (Gourine et al., 2005).

Our study focused entirely on respiratory chemoreceptors in the $\mathrm{RTN}$, providing a direct test of the role of $\mathrm{P} 2$ receptors in $\mathrm{pH}$ sensitivity of these neurons. This focus is appropriate because these neurons meet key criteria expected for consideration as central respiratory chemoreceptors (Mulkey et al., 2004), and they are located in the region in which increases in ATP were measured during a hypercapnic challenge in vivo (Gourine et al., 2005). Given that the cells responsible for hypercapnia-induced ATP release are capable of sensing and responding to changes in $\mathrm{CO}_{2}$, it is interesting to speculate that the chemosensitive neurons we have identified in the RTN might themselves be responsible for release of ATP in the ventral medulla during hypercapnia.

Our data clearly indicate that $\mathrm{P} 2$ receptor signaling is not required for intrinsic $\mathrm{pH}$ sensitivity of the RTN neurons in our sample. However, it remains possible that some other population of chemosensitive neurons, located elsewhere in the RTN or brainstem, may rely on purinergic mechanisms for their response to changes in $\mathrm{pH}$. In this respect, it is worth noting that $\mathrm{CO}_{2}$ enhanced respiratory neural output from a brainstem-spinal cord preparation, which should include most additional presumptive respiratory chemosensitive neurons, was also unaffected by block of P2 receptors (Lorier et al., 2004). Interestingly, ATP itself stimulated respiratory output from that in vitro preparation, independent of changes in $\mathrm{CO}_{2}$ sensitivity, also leading to the conclusion that purinergic signaling can modulate respiratory neuronal activity without directly affecting chemosensitivity (Lorier et al., 2004). It seems likely that the attenuation of $\mathrm{CO}_{2}$-enhanced respiratory output by PPADS in vivo (Gourine et al., 2005), at least in part, reflects block of $\mathrm{P} 2$ receptor stimulation of these other components of the respiratory control system, downstream of central respiratory chemoreceptors.

Over the last four decades, despite significant progress in identification of candidate brainstem regions involved in respiratory chemoreception (Dean et al., 1990; Coates and Nattie, 1993; Huang et al., 1997) and of candidate ion channels that can impart an intrinsic neuronal $\mathrm{pH}$ sensitivity, the neuronal and molecular substrates for central respiratory chemosensitivity remain largely undefined (Bayliss et al., 2001; Jiang et al., 2001; Putnam et al., 2004). We have proposed (Mulkey et al., 2004) that a group of $\mathrm{pH}$-sensitive RTN neurons represent the elusive ventral medullary respiratory chemoreceptors sought since the early 1960s (Mitchell et al., 1963) and that a $\mathrm{pH}$-sensitive background $\mathrm{K}^{+}$ current contributes to RTN neuronal chemosensitivity (Mulkey et al., 2004). However, the molecular identity of the underlying
$\mathrm{K}^{+}$channel remains to be determined, and a definitive test of our proposal awaits development of molecular genetic models that disrupt function of the $\mathrm{pH}$-sensitive $\mathrm{K}^{+}$channel or the RTNchemosensitive neurons. Such a test has already been performed for the highly $\mathrm{pH}$-sensitive $\mathrm{P}_{2} \mathrm{X}_{2}$ receptor subtypes originally implicated in central respiratory chemosensitivity (Thomas et al., 1999); in $\mathrm{P}_{2} \mathrm{X}_{2}$ receptor knock-out mice, the ventilatory response to raised $\mathrm{CO}_{2}$ was fully intact (Rong et al., 2003). This result from a mouse with a specific $\mathrm{P} 2$ receptor subtype deletion is exactly as we would predict from our current studies and those of Lorier et al. (2004), in which $\mathrm{CO}_{2} / \mathrm{pH}$ sensitivity was retained in individual chemoreceptors or in a chemosensitive respiratory neuronal preparation despite nonselective block of multiple $\mathrm{P} 2$ receptors.

In conclusion, RTN chemoreceptors are indirectly inhibited by $\mathrm{P} 2 \mathrm{X}$ receptor-mediated GABA/glycine release and directly excited via a $\mathrm{P} 2 \mathrm{Y}$ receptor-mediated mechanism; neither $\mathrm{P} 2$ receptor mechanism accounts for RTN neuron chemosensitivity but both may contribute to integrated respiratory responses that accompany $\mathrm{CO}_{2}$-evoked ATP release.

\section{References}

Bayliss DA, Talley EM, Sirois JE, Lei Q (2001) TASK-1 is a highly modulated $\mathrm{pH}$-sensitive "leak" $\mathrm{K}^{+}$channel expressed in brainstem respiratory neurons. Respir Physiol 129:159-174.

Coates EL, Nattie EE (1993) Widespread sites of brain stem ventilatory chemoreception. J Appl Physiol 75:5-14.

Dean JB, Bayliss DA, Erickson JT, Lawing WL, Millhorn DE (1990) Depolarization and stimulation of neurons in nucleus tractus solitarii by carbon dioxide does not require chemical synaptic input. Neuroscience 36:207-216.

Dulla CG, Dobelis P, Pearson T, Frenguelli BG, Staley K, Masino SA (2005) Adenosine and ATP link $\mathrm{PCO}_{2}$ to cortical excitability via $\mathrm{pH}$. Neuron 48:1011-1023.

Feldman JL, Mitchell GS, Nattie EE (2003) Breathing: rhythmicity, plasticity, chemosensitivity. Annu Rev Neurosci 26:239-266.

Gourine AV, Llaudet E, Dale N, Spyer KM (2005) ATP is a mediator of chemosensory transduction in the central nervous system. Nature 436:108-111.

Huang R-Q, Erlichman JS, Dean JB (1997) Cell-cell coupling between $\mathrm{CO}_{2}$ excited neurons in the dorsal medulla oblongata. Neuroscience 80:41-57.

Jiang C, Xu H, Cui N, Wu J (2001) An alternative approach to the identification of respiratory central chemoreceptors in the brainstem. Respir Physiol 129:141-157.

Lorier AR, Peebles K, Brosenitsch T, Robinson DM, Hosley GD, Funk GD (2004) P2 receptors modulate respiratory rhythm but do not contribute to central $\mathrm{CO}_{2}$ sensitivity. in vitro. Respir Physiol Neurobiol 142:27-42.

Mitchell RA, Loeschcke HH, Massion WH, Severinghaus JW (1963) Respiratory responses mediated through superficial chemosensitive areas on the medulla. J Appl Physiol 18:523-533.

Mulkey DK, Stornetta RL, Weston MC, Simmons JR, Parker A, Bayliss DA, Guyenet PG (2004) Respiratory control by ventral surface chemoreceptor neurons in rats. Nat Neurosci 7:1360-1369.

Putnam RW, Filosa JA, Ritucci NA (2004) Cellular mechanisms involved in $\mathrm{CO}_{2}$ and acid signaling in chemosensitive neurons. Am J Physiol Cell Physiol 287:C1493-C1526.

Ralevic V, Burnstock BG (1998) Receptors for purines and pyrimidines. Pharmacol Rev 53:413-492.

Ritucci NA, Erlichman JS, Leiter JC, Putnam RW (2005) Response of membrane potential and intracellular $\mathrm{pH}$ to hypercapnia in neurons and astrocytes from rat retrotrapezoid nucleus. Am J Physiol Regul Intergr Comp Physiol 289:R851-R861.

Rong W, Gouring AV, Cockayne DA, Xiang Z, Ford AP, Spyer KM, Burnstock G (2003) Pivotal role of nucleotide P2SX2 receptor subunit of the ATPgated ion channel mediating ventilatory responses to hypoxia. J Neurosci 23:11315-11321.

Thomas T, Ralevic V, Gadd CA, Spyer KM (1999) Central CO 2 chemoreception: a mechanism involving P2 purinoceptors localized in the ventrolateral medulla of the anaesthetized rat. J Physiol (Lond) 517:899-905. 